\title{
MCP-1 expression is specifically regulated during activation of skeletal repair and
} remodeling.

Wu AC, Morrison NA, Kelly WL, Forwood MR

School of Medical Science and Griffith Health Institute, Griffith University, Gold Coast Campus, Australia 4222

\section{Correspondence}

Prof Mark R. Forwood

School of Medical Science

Griffith University, Gold Coast Campus, Australia 4222

Tel +61 755527305

Fax +61755527053

Email: m.forwood@griffith.edu.au 


\begin{abstract}
Monocyte chemotactic protein-1 (MCP-1) belongs to the $\mathrm{CC}$ chemokine superfamily and plays a critical role in recruitment and activation of leukocytes during acute inflammation. We hypothesize that MCP-1 is also an important chemokine regulating recruitment and activation of bone cells required for skeletal repair and remodeling. We used the ulnar stress fracture (SFx) model that allows investigation of focal remodeling with a known time course and precise anatomical location. SFx were created in the right ulna of female Wistar rats using cyclic end-loading. Unloaded animals were used as a control. Rats were euthanized 4h, 1, 4, 7 and 14 days after loading ( $n=10$ /group) and RNA extracted and converted to cDNA for quantitative PCR analysis using TaqMan gene expression assays. Four hours after loading, MCP-1 gene expression was increased $\sim 30$-fold $(\mathrm{P}<0.001)$, remained elevated at $24 \mathrm{~h}(\sim 12$ fold, $\mathrm{P}<0.001)$, then declined by day 14 . Relative to contralateral limb, expression of the receptors CCR1 and CCR2 increased over the 14 days, being significant by 4 days for CCR 1 and 14 days for CCR2 $(\mathrm{P}<0.05)$. Other inflammatoryrelated chemokines (RANTES, MIP1a) were not increased at these early time-points. Using in-situ hybridization and immunohistochemistry in separate animal groups ( $\mathrm{n}=5$ /group, control, day 1, 4 7), MCP-1 mRNA and protein was localized in periosteal osteoblasts associated with woven bone formation at the fracture exit point, but not within osteocytes adjacent to the SFx. These data support an important role for MCP-1 in the early phase of SFx repair and activated remodeling.
\end{abstract}

Keywords: bone remodeling, chemokine, monocyte chemotactic protein-1, stress fracture 


\section{Introduction}

Bone remodeling occurs throughout life and is necessary to maintain the integrity of cortical and cancellous bone. It turns over aged bone tissue, removes skeletal microdamage, reorganizes fracture callus and repairs stress fractures (SFx) [1]. This highly coordinated process ensures that skeletal integrity is maintained. Conversely, dysregulated bone remodeling impairs bone quality and is central to many diseases of bone, such as osteoporosis and Paget's disease. Basic multicellular units (BMUs) are formed during remodeling and consist of osteoclasts, osteoblasts and their precursors. Following an activation event, remodeling progresses by resorption of bone matrix followed by new bone formation until a new bone structural unit is completed. Bone marrow and bone are anatomically contiguous and form a functional unit, whereby the bone marrow niche provides sources of haematopoietic and non-haematopoietic stem cells that are precursors for bone and immune cells. Fundamental mechanisms that initiate remodeling events, like recruitment of cells to the BMU, are not well understood; but chemokines are strong contenders for regulating cell attraction to a BMU during remodeling activation.

Cells of the immune system secrete chemokines and cytokines. Chemokines, are small molecular weight proteins $(8-10 \mathrm{kDa})$ that are important for host defence systems and normal tissue maintenance. They are divided into 4 subfamilies $\left(\mathrm{CC}, \mathrm{CXC}, \mathrm{C}, \mathrm{CX}_{3} \mathrm{C}\right)$, based on the spacing of the first two, conserved, cysteine residues. The role of chemokines in the immune system has been extensively studied [2,3]; but knowledge of their interactions in bone cell biology remains rudimentary. Under pathological conditions, osteoblasts increase production of CCL20 (macrophage inflammatory protein 3 alpha, MIP3 $\alpha$ ) compared to those from normal tissues [4]. CCL20 also induces osteoclast differentiation by increasing the number of osteoclast progenitors and assists cell fusion via the production of matrix metalloproteinase-9 (MMP-9) [4]. It is also

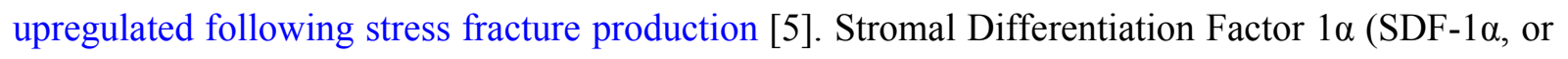
CXCL12) increases osteoclast resorption, size of resorption pits and number and elevated 
expression of RANKL, Cathepsin K, MMP-9 and TRAP when cultured with peripheral bloodderived osteoclast precursors [6]. We also observed a modest increase in gene expression for SDF1 following SFx initiation in vivo [1]. Similarly, macrophage inflammatory protein $1 \alpha$ (MIP1 $\alpha$, or CCL3) acts directly on osteoclast progenitors to enhance osteoclast formation [7,8]. Many cytokines and chemokines also regulate osteoblast $[9,10]$ and osteoclast function $[11,12]$. In addition, gene array studies demonstrate that chemokine expression associated with angiogenesis, eg CXCL10 and -13 , increases soon after SFx in the rat ulna [5].

Monocyte chemotactic protein-1 (MCP-1, or CCL2) is a member of the CC chemokine superfamily that plays a critical role in the recruitment and activation of leukocytes during acute inflammation [1,13]. In addition, MCP-1 is found at the site of tooth eruption, a feature consistent with a role in osteoclast biology [14]. Importantly, MCP-1 is induced by RANKL and promotes osteoclast fusion into multinuclear cells [15]. Moreover, following treatment of rats with parathyroid hormone (PTH), MCP-1 was the highest induced gene on array analysis, being induced by an order of magnitude greater than the next 3 candidate genes identified [16]. In the anabolic regime, PTH caused MCP-1 induction to increase over time until it was $>200$ fold after 14 days of treatment. While numerous chemokines provide regulation of both chemotaxis and osteoclast differentiation during inflammatory bone remodeling, we hypothesize that MCP-1 is specifically regulated in skeletal repair and physiological remodeling.

We previously observed an upregulation of cytokines such as IL-6 during early phase of SFx healing, and this peak of expression coincided with the initiation of woven bone formation, suggesting IL-6 involvement in the signaling of new bone formation. Oncostatin M, another cytokine that stimulates bone resorption [17], is also expressed by osteoblasts and acts locally to promote bone formation and resorption in vitro [18]. Our aim is to determine if oncostatin $\mathrm{M}$ is regulated coincidently with MCP-1 in vivo in skeletal repair and remodeling. 
We have optimized a rat model of SFx that presents an approach to examine focal bone remodeling with a known time course and precise anatomical location [1,19]. This offers an opportunity to explore cellular signaling of bone remodeling in vivo, in particular the involvement of chemokines and cytokines during skeletal repair. Our specific aim is to investigate the expression of chemokines in the CC family (MCP-1, RANTES, MIP1 $\alpha$ ) and a cytokine involved in bone formation (Oncostatin-M, OSM) and their receptors (CCR1, CCR2, OSMr) during initiation and progression of remodeling that repairs the SFx in the rat ulna.

\section{Materials and methods}

\section{Experimental animals}

A total of 98 female Wistar rat age 17-18 weeks with an average weight of $322 \pm 3 \mathrm{~g}$ were purchased from The University of Queensland Biological Resources Unit, housed in pairs and allowed ad libitum feeding and free cage activity between loading session. Experiments were approved by the Griffith University Animal Ethics Committee and followed NHMRC guidelines for the care and use of laboratory animals. For gene expression studies, a total of 5 experimental groups from 4 hours to 14 days post-loading were examined (4h, Day 1 , Day 4 , Day 7 , Day $14 ; n=10$ per group, except $n=8$ for 4h). An unloaded control group (ULC) provided baseline control values. For in-situ hybridization (ISH) and immunohistochemistry (IHC), separate experimental groups were used (ULC, Day 1, Day 4, Day 7) with n=5 per group.

\section{Ulna loading to create SFx}

The loading regime followed our previously published protocol [1]. Briefly, the animals were anesthetized with Isoflourane and their forelimbs were positioned in a custom designed mechanical device. SFx was generated on the ulna by axial compressive cyclic loading with applied load between 17-30 $\mathrm{N}$ and $2 \mathrm{~Hz}$ cycle frequency. LabChart v7.1 (AD Instruments, Colorado Springs, USA) was used to monitor the displacement curve and the loading was manually stopped when a 
$10 \%$ increase in displacement value was reached. The average total number of loading cycles for the experiment was $10,645 \pm 447$ (mean \pm SD). A single subcutaneous injection of an opioid analgesic (Buprenorphine, $0.05 \mathrm{mg} / \mathrm{Kg}$ ) was used following each loading session. No sign of behavioral changes was observed in experimental animals after loading.

ULC and contralateral left ulnae of loaded rats were used as negative controls. At each time point after loading, rats were euthanized using $\mathrm{CO}_{2}$ asphyxiation, and right (loaded) and left ulnae were dissected, soft tissue removed (except for periosteum) and snap-frozen in liquid nitrogen and stored at $-80^{\circ} \mathrm{C}$ until use. At euthanasia, blood was collected via cardiac puncture into a $3 \mathrm{~mL} \mathrm{BD}$ Vacutainer ${ }^{\circledR}$ blood collection tube (BD Biosciences, USA). The tubes were inverted several times and incubated at 30 minutes at room temperature and centrifuged at $1300 \mathrm{~g}$ for 10 minutes to allow phase separation. The clear serum was collected and stored at $-20^{\circ} \mathrm{C}$ until use.

\section{RNA extraction}

Total RNA was extracted from the bone using Trizol protocol as previously described [1]. Briefly, the epiphyses were dissected and the ulnar diaphyses were ground into fine powder in liquid nitrogen by using a mortar and pestle. The ground bone powder was homogenized with $1 \mathrm{~mL}$ of Trizol and spun at $12,000 \mathrm{~g}$ for $10 \mathrm{~min}$ at $4{ }^{\circ} \mathrm{C}$. The supernatant was collected and mixed with 200 $\mu \mathrm{L}$ of chloroform and spun at $12,000 \mathrm{~g}$ for $15 \mathrm{~min}$ at $4^{\circ} \mathrm{C}$ to allow phase separation. The clear aqueous phase was collected and the RNA was precipitated using glycogen and isopropanol overnight at $-20^{\circ} \mathrm{C}$. RNA was extracted again using phenol chloroform to remove impurities and the pellet was resuspended in $11 \mathrm{uL}$ of RNAse DNase free water (Invitrogen). RNA was quantified using Nanodrop1000 (ThermoScientific, USA) to determine yield and purity. RNA yield (mean \pm SD) for the right ulna was $326 \pm 28 \mathrm{ng} / \mu \mathrm{L}$ and the left ulna was $322 \pm 28 \mathrm{ng} / \mu \mathrm{L}$. 


\section{qRT-PCR}

RNA was treated with DNase I (Promega, Australia) following the manufacturer's protocol to remove genomic DNA contamination. RNA was converted to cDNA using ImProm-II reverse transcriptase (Promega, Australia) and oligo dT primers. Taqman primers were used to detect the target genes (Table 1). Quantitative real time PCR (qPCR) was used to detect the expression of chemokines and cytokine using the BioRad CFX96 real time PCR detection system (BioRad, Australia). The PCR cycling condition was: $95^{\circ} \mathrm{C}$ for $10 \mathrm{~min}$ to activate the Taq polymerase, followed by 40 cycles of annealing and extension step at $95^{\circ} \mathrm{C}$ for $15 \mathrm{~s}$ and $58^{\circ} \mathrm{C}$ for $70 \mathrm{~s}$. The mRNA transcripts level for each gene was normalized and expressed relative to the average expression of HPRT and GAPDH housekeeping genes.

\section{Serum ELISA}

The detection of MCP1 in the serum was performed using a commercially available BD OptEIA ${ }^{\mathrm{TM}}$ Rat MCP-1 ELISA set (BDBioscience, USA). The ELISA was performed following the manufacturer's protocols. Briefly, the 96 wells plate was coated with capture antibody at $4{ }^{\circ} \mathrm{C}$ overnight. The plate was aspirated and washed with phosphate buffered saline (PBS) $/ 0.05 \%$ Tween and blocked with $10 \% \mathrm{FCS} / \mathrm{PBS}$ at room temperature for $1 \mathrm{~h}$. The plate was aspirated and washed and the standards or serum (diluted 1:100) was added to their corresponding well and incubated at room temperature for $2 \mathrm{~h}$. The plate was aspirated and washed followed by the addition of working detector (detection $\mathrm{Ab}+$ Streptavidin-HRP) and incubate for $1 \mathrm{~h}$ at room temperature. The plate was aspirated and washed followed by the addition of 3,3',5,5'-tetramethylbenzidine (TMB) substrate solution to each well and incubated for $15 \mathrm{~min}$. The reaction was stopped by addition of $2 \mathrm{M} \mathrm{H}_{2} \mathrm{SO}_{4}$ and the absorbance was measured at $450 \mathrm{~nm}$ using a plate reader.

\section{Riboprobe synthesis}

cDNA plasmid templates were generated using PCR to amplify MCP-1 sequences from rat bone cDNA using specific primers (Forward 5'- CAGGTCTCTGTCACGCTTCT -3', Reverse 5'- 
AGTATTCATGGAAGGGAATAG-3'). The PCR products were gel extracted and purified using commercial kits (Promega, Australia) and ligated into the multiple cloning sites (MCS) of pGEM-T Easy vector (Promega, Australia). The plasmid vector sequence was confirmed by DNA sequencing (DNA Sequencing Facility, Griffith University). Sense and antisense RNA probes were synthesized using T7 and SP6 DNA-dependent RNA polymerase promoters that are adjacent on each end of the MCS of the plasmid. After linearization of the template DNA using Sac I and Sac II restriction enzymes (New England Biolabs, USA), riboprobe synthesis reaction consists of (digoxigenin-)DIG-UTP (Roche, Australia), reaction buffers, placental RNAse inhibitor and the appropriate RNA polymerase (Roche, Australia). The labeling conditions followed manufacturer's instructions. The labeled probe was treated with DNase I and purified using ethanol precipitation. The RNA probe integrity was characterized by gel electrophoresis and concentration quantified by Nanodrop spectrometer (Thermo, Australia). The RNA probe was stored at $-80^{\circ} \mathrm{C}$ until use.

\section{In situ hybridization}

Paraffin sections were de-waxed through three changes of xylene and descending concentration of ethanol. After de-waxing, the tissue was first treated with $0.2 \mathrm{M} \mathrm{HCL}$ for 20 minutes to eliminate endogenous alkaline phosphatase activity followed by digestion with $5 \mu \mathrm{g} / \mathrm{mL}$ of proteinase $\mathrm{K}$ (in $100 \mathrm{mM}$ Tris-HCL pH8.0, 50mM EDTA) for 30 minutes at $37^{\circ} \mathrm{C}$. Proteinase $\mathrm{K}$ activity was stopped by soaking sections in $2 \mathrm{mg} / \mathrm{mL}$ glycine made up in PBS for 5 minutes and washed with two changes of PBS. The section was then refixed in 4\% PFA made up in PBS for 15 minutes at room temperature, rinsed in several changes of PBS and diethylpyrocarbonate (DEPC)-treated water. Sections were equilibrated in hybridization buffer $(50 \%$ formamide, $5 \times$ SSC, $2 \%$ block reagent, $0.02 \%$ SDS, $0.1 \% \mathrm{~N}$-lauroylsarcosine) for 1 hour at $42^{\circ} \mathrm{C}$ in a humidified chamber and incubated with $1 \mathrm{ng} / \mu \mathrm{L}$ of respective RNA probe at $42^{\circ} \mathrm{C}$ overnight. Sections were sequentially washed with descending concentrations of standard saline citrate $(2 \times, 1 \times, 0.1 \times)$ for 15 minutes each (two changes) and rinsed briefly with $100 \mathrm{mM}$ Tris $\mathrm{pH} 7.5,150 \mathrm{mM} \mathrm{NaCl}$. Sections were incubated with the same buffer, but containing $1 \%$ blocking reagent for 30 minutes, in a humidified chamber 
at room temperature; followed by 1 hour room temperature incubation with 1:500 dilution of antidigoxigenin-alkaline phosphatase (DIG-AP) antibody (made up in Buffer 2). The sections were washed with two changes of buffer 1 for 15 minutes each and equilibrated in buffer 3 (100mM Tris$\mathrm{HCL}, 100 \mathrm{mM} \mathrm{NaCl}, 50 \mathrm{mM} \mathrm{MgCl} 2, \mathrm{pH} 9.5)$ for three minutes. For color development, sections were incubated with $250 \mu \mathrm{L}$ of color substrate solution (consists of $45 \mu \mathrm{L} 75 \mathrm{mg} / \mathrm{mL}$ NBT solution $+35 \mu \mathrm{L} 50 \mathrm{mg} / \mathrm{mL}$ x-phosphate made up in $10 \mathrm{~mL}$ solution 3, filter sterilize) at room temperature. Color development was monitored every hour and the reaction stopped by incubating the sections with buffer 4 (10mM Tris-HCL, 1mM EDTA, pH8.0). Stained sections were mounted in $0.2 \%$ propyl gallate in $\mathrm{PBS} / 50 \%$ glycerol. Controls included the sense probe or omission of probes and anti-DIG-AP antibody sections.

\section{Immunohistochemistry}

Anti-rat MCP-1 primary antibody and its respective isotype control were purchased commercially (Abcam, Massachusetts, USA). Sections were deparaffinised using xylene and rehydrated through descending concentration of ethanol. Antigen retrieval was performed using microwave heating in $10 \mathrm{mM}$ EDTA buffer, and the sections were washed with Tris-buffered saline (TBS) for $5 \mathrm{~min}$ following antigen retrieval. The elimination of non-specific protein binding was performed by incubating the sections with $10 \%$ fetal calf serum (made up in TBS) for $1 \mathrm{~h}$ at room temperature. Specimens were then incubated at $4^{\circ} \mathrm{C}$ overnight with the primary antibody diluted to $5 \mu \mathrm{g} / \mathrm{mL}$ made up in TBS. Normal rabbit $\operatorname{IgG}(5 \mu \mathrm{g} / \mathrm{mL}$, Santa Cruz, USA), was used as respective isotype controls. The following day, the sections were washed with TBS for $5 \mathrm{~min}$ followed by the elimination of endogenous peroxidase activity by blocking with $3 \% \mathrm{H}_{2} \mathrm{O}_{2}$ for 30 min at room temperature. The sections were washed with TBS and incubated with $2 \mu \mathrm{g} / \mathrm{mL}$ of goat anti rabbit biotinylated IgG secondary antibodies (made up in TBS) for $30 \mathrm{~min}$ at room temperature followed by $5 \mathrm{~min}$ wash with TBS. Sections were incubated with streptavidin-horseradish peroxidase 
complex (Dakocytomation, Australia) diluted 1:300 in TBS for 30 min followed by 5 min washes with TBS. The streptavidin-horseradish peroxidase activity was detected by incubating the sections with liquid diaminobenzidine chromogen (Dakocytomation, Australia) for a predetermined time, followed by washing for $5 \mathrm{~min}$ in deionized water. Sections were counterstained with Mayer's haematoxylin for $1 \mathrm{~min}$ followed by rinsing in running tap water for $5 \mathrm{~min}$. The sections were then dehydrated overnight and mounted in Cytoseal permanent mounting media (ProSciTech, Australia).

\section{Microscopy}

Sections were examined using bright field optics on an Olympus BX60 microscope. Classification of cells was based on morphology and all the immunostained slides were counterstained with hematoxylin to allow visual identification of the cells. Sections for ISH were not counterstained. Sections were examined from each time point from Day 1, 4 and 7, but cell-based morphometry was not quantified because woven bone confounded the surface observations, and osteocytes did not express the MCP-1 protein or mRNA.

\section{Statistical analysis}

Differences among groups in gene expression were analyzed using one-way ANOVA with post hoc analysis of between group differences using Fisher's protected least significant difference test (SPSS 17.0; SPSS Inc., USA). Significance was determined at $\mathrm{P}<0.05$. Fold differences between the loaded (right) and the opposite unloaded (left) ulnae were determined for each time point and paired t-tests were performed to determine the significant differences. For all tests, significance level was determined at $\mathrm{P}<0.05$ or greater.

\section{Results}

\section{Gene expression in unloaded ulna}

To determine basal expression of our target genes in bone, mRNA expression was examined in ulna from unloaded animals (Figure 1). The expression of each gene varied quite markedly in the tissue, 
with MIP1 $\alpha$, OSM and OSMr expressed at the lowest level. There were no significant differences between MCP-1 mRNA expression with RANTES, CCR1 and CCR2 (P>0.05). However, the mRNA level of MCP-1 was 164 times higher than MIP1 $\alpha(\mathrm{P}<0.001), 36$ times that of OSM $(\mathrm{P}<0.001)$ and about 9-fold higher than OSMr $(\mathrm{P}<0.01)$. Nonetheless, the target genes under investigation were expressed in bone tissue.

\section{Gene expression in SFx ulna}

Following loading, MCP-1 was the only chemokine that significantly increased its gene expression compared to the ULC (Table 2, Figure 2). At 4 hours, MCP-1 gene expression was $\sim 30$-fold higher $(\mathrm{P}<0.001)$ than ULC; and this had declined to 12 -fold by Day 1 [day 1 or 24 hours] $(\mathrm{P}<0.001)$. By D4, MCP-1 expression dropped to 3-fold increase with the expression maintained at this level until D14. For the 2 weeks post-loading, MCP-1 expression remained elevated when compared to ULC (Figure 2A). Both the chemokine receptors CCR1 and CCR2 showed a marginal increase, with mRNA expression of CCR1 peaking by Day 4 (2.4 fold, $\mathrm{P}<0.05$ ) and CCR2 by Day 14 (4 fold, $\mathrm{P}<0.05$ ) compared to ULC. CCR2 also showed significant increases at each time-point when compared to the contralateral ulna (Table 2).

Compared to ULC, MIP1 $\alpha$, RANTES, OSM and OSMr showed no significant increase in expression. But, when compared to unloaded contralateral limbs (Table 2), OSMr showed a small 2.3 fold induction $(\mathrm{P}<0.0002)$. At Day 4, RANTES showed a small 1.7-fold increase $(\mathrm{P}<0.01)$; and, at Day 7, MIP1 $\alpha$ increased by 4.2-fold $(\mathrm{P}<0.002)$.

\section{MCP-1 serum level}

To determine if the observed MCP-1 mRNA peak is tissue specific, or has significant effect on the systemic level of MCP-1 in the rat, serum MCP-1 protein were measured by ELISA. Similar to the gene expression data, the serum protein level of $\mathrm{MCP}-1$ peaked by day 1 ( 1.5 fold, $\mathrm{P}<0.001)$ and dropped to basal level by day 4 . 


\section{In-situ hybridization and immunohistochemistry}

Based on the gene expression study, MCP-1 was examined using ISH and IHC analysis. MCP-1 localization in rat ulna was performed to determine which cell types express this chemokine around the SFx region. Day 7 post-loading was chosen for Fig 3 (ISH) because woven bone formation reaches its maximum by that time, and coincides with the appearance of BMUs at this site. For IHC (Fig 4), images from days 1, 4 and 7 are included to demonstrate protein expression in bone cells at these time-points. Moderate staining of MCP-1 mRNA was localized in periosteal osteoblasts from Day 1 and osteoblasts within the woven bone at Day 7. Osteocytes adjacent to, or distant from, the SFx were negative for MCP-1. Cells within the bone marrow cavity also showed mRNA expression for MCP-1 (Fig 3). Immunohistochemical localization of MCP-1 protein showed similar pattern of expression as its mRNA (Fig 4). MCP-1 protein was predominately localized in periosteal osteoblasts (Fig 4A), osteoblasts in the woven bone (Fig 4B and C) and some of the bone marrow cells (Fig 4F). Other cell types that showed positive staining for MCP-1 protein are stromal cells at the periosteal surface and chondrocytes at the growth plate (data not shown).

\section{Discussion}

The role of chemokines in immune regulation has been extensively studied, but less so their regulation of activated bone remodeling. Under baseline physiological conditions, gene expression for the chemokines MCP-1, RANTES, MIP1 $\alpha$, and their receptors were detected in bone with varying degrees of expression. Following initiation of SFx, MCP-1 was specifically regulated, compared to the other chemokines examined, with increased gene expression during the early stage of remodeling activation (Figure 2, Table 2). This was further confirmed by the elevation of serum MCP-1 concentration 24 hours after loading. The chemokine receptor, CCR 1 also increased relative to the unloaded control from day 4 to 14 , and CCR2 at day 14 . When compared to the contralateral ulna, both chemokine receptors, CCR1 and 2, showed increased gene expression from day 4 and 4 hours, respectively. Other candidate chemokines typically associated with inflammatory mediators 
(RANTES, MIP1 $\alpha$ ), and the cytokine OSM showed no consistent increase during 14 days following SFx.

Combined with the significant increase in MCP-1 expression associated with PTH treatment in rats [16], these data point to an important role for MCP-1 in the activation phase of SFx healing and bone remodeling. In the anabolic protocol, MCP-1 exhibited the greatest increase in gene expression on array analysis following PTH treatment [16]. Several other lines of evidence demonstrate involvement of the CC chemokine subfamily (MCP-1, RANTES, MIP1 $\alpha$ ) in pathological bone conditions such as multiple myeloma [7], rheumatoid arthritis and osteoarthritis $[20,21]$. Increased activity of osteoclasts is a common phenotype of these bone conditions that lead to osteolysis. Unlike these immune associated bone conditions, PTH treatment and SFx are not associated with an inflammatory cascade. However, they do share common signaling pathways, such as those sharing the gp-130 co-receptor sub unit, such as IL-6 and IL-11 that regulate RANKL/OPG signaling $[1,22]$, and signaling via $\mathrm{PGE}_{2}$ stimulation of cAMP $[23,24]$.

Both woven bone formation and bone remodeling require angiogenesis to support the bone cell activity. The increase in angiogenic chemokines observed following SFx [5] is highly consistent with the increase in MCP1 observed here, because both chemokines attract the cells required to support the tissue repair and remodeling. Localization of MCP-1 was observed in periosteal osteoblasts at the SFx site (Fig. 3), supporting a hypothesis that osteoblastic expression of MCP-1 is involved in osteoclast recruitment and differentiation at the stage of osteoclastogenesis. That process is initiated simultaneously with the increase in woven bone formation that stabilizes the exit point of the SFx. It is difficult to separate the signaling events regulating these biological processes. Nonetheless, the activation of the periosteum, and the increase in bone formation activity, provides a rich source of osteoblastic cells capable of signaling via MCP1 expression. Collectively, our data implicate MCP-1 as an important molecule for signaling the activation phase of remodeling. A limitation of this conclusion is that we have not specifically tested the effect of MCP1 inhibition. 
Osteoblastic cells are critical partners in recruitment of osteoclast progenitors from the circulation to remodeling sites, and several chemokines regulate this process. For example, SDF1 (CXCL12), CCL9 (MIP-1 $\gamma$ ) and CCL1 play a role in osteoclast attraction, fusion and/or bone resorption ([2527]). Our group previously reported that MCP-1 also promotes human osteoclast fusion $[15,28]$. In those experiments, cells treated with MCP-1, but without RANKL, formed $\mathrm{TRAP}^{+}$multinuclear cells that closely resembled osteoclasts, but were unable to resorb bone [15]. GM-CSF overrides the osteoclast differentiation pathway, leading to dendritic cells even in the presence of RANKL. In that process, GM-CSF suppressed the RANKL-mediated induction of MCP-1. However, adding back MCP-1 resulted in the reversal of GM-CSF repression of osteoclast differentiation, suggesting that MCP-1 has a number of different potent effects on osteoclast differentiation [15].

We demonstrated that SFx heals by direct remodeling, by which BMUs migrate along the SFx line to repair the damage [1]. In this model, increases in gene and protein expression of target molecules can be unequivocally related to the remodeling event initiated by SFx. This is because rat cortical bone does not undergo secondary remodeling under normal conditions, and changes in molecular events can be precisely linked to osteoclastogenesis and origination of a BMU. Unlike other chemokines we have investigated (Table 2; [1]), MCP-1 was significantly increased within 4 hours of the activation phase of remodeling, suggesting a key role in the recruitment of precursor cells to the site of remodeling, and bone formation.

In the anabolic application of ulnar loading, in which SFx was not generated, microarray analysis identified a group of chemokines, including MCP-1, that were upregulated within 4 hours of loading [29]. These were down-regulated later in the time course of adaptation when matrix formation was initiated. Although, the SFx protocol engenders a remodeling response, it also initiates early woven bone formation at the fracture exit point to stabilize the SFx [1]. In our model, both chemokine receptors CCR1 and CCR2 were moderately increased up to day 14 after the initiation of SFx; whereas Mantila et al., (2010) supported a down regulation of these genes during the matrix formation phase of adaptation (up to 5 weeks after loading). The discrepancy between 
these data likely relates to the activation of remodeling in the SFx model, and the fact that loading of the right ulna exerts a systemic effect on the left contralateral unloaded ulna in the SFx protocol $[1,30]$. Mantila et al (2010) used only contralateral controls making interpretation of data difficult, but reinforcing the importance of ULC as we have done.

We localized MCP-1 mRNA and protein in osteoblasts within the woven bone and stromal cells adjacent to the SFx site. From our experience with this model, osteoclasts are observed one week after SFx, with the appearance of BMU migrating along the SFx line by 2 weeks. Localization of MCP-1 at a site destined for remodeling is consistent with our hypothesis that chemokines are activated to recruit osteoclasts and their precursor cells to the site of remodeling. We also know that inflammatory cells are absent at the SFx site [1], supporting our observations that osteoblasts are the main cell type to synthesize MCP-1 protein during skeletal repair.

We have found OSM and OSMr to be expressed at a low level in unloaded rat ulnae when compared to house keeping genes (Figure 1A). Following SFx initiation, there was no significant increase in the mRNA expression of OSM and its receptor. Conversely, Mantila et al., (2010) showed an upregulation at $4 \mathrm{~h}$ after adaptive mechanical loading. OSM induces osteoblast proliferation and collagen synthesis [31], and promotes bone formation [18] in vitro. During differentiation of primary murine osteoblasts, or Kusa4b10 cells, expression of OSM and its receptor increases as osteoblastic cells mature from day 7 to 14 . The principal "adaptive" response to ulnar loading is new lamellar bone formation, in contradistinction to the SFx model in which woven bone formation and bone remodeling occur. OSM, therefore, appears to be more concerned with regulation of bone matrix formation, than early signaling of the BMU progenitors.

In conclusion, we identified that the chemokine MCP-1 is specifically regulated during the early phase of remodeling following SFx initiation. MCP-1 mRNA and protein were localized in osteoblasts adjacent to the SFx. Because MCP-1 is secreted by osteoblasts, and its receptor CCR2 can be found in osteoclasts [28], it is a strong candidate as an important signaling molecule attracting osteoclasts and its precursors to the site of bone remodeling. 


\section{Acknowledgments}

DISCLOSURES: NONE. This study was supported in part by National Health and Medical Research Council Project Grants (511187, 597481 and APP1049190); the Rebecca L Cooper Medical Research Foundation; and a Griffith University New Staff Research Grant to ACW. Those funding agencies had no role in study design; data collection, analysis or interpretation; nor in the writing of the report or the decision to submit the article for publication. We thank Mr Bradley Paterson for expert histotechnical assistance.

\section{References}

1. Kidd LJ, Stephens AS, Kuliwaba JS, Fazzalari NL, Wu AC, Forwood MR (2010) Temporal pattern of gene expression and histology of stress fracture healing. Bone 46 (2):369-378. doi:10.1016/j.bone.2009.10.009

2. Ley K (2003) Arrest chemokines. Microcirculation 10 (3-4):289-295. doi:10.1038/sj.mn.7800194 3. Moser B, Willimann K (2004) Chemokines: role in inflammation and immune surveillance. Ann Rheum Dis 63 Suppl 2:ii84-ii89. doi:10.1136/ard.2004.028316

4. Lisignoli G, Piacentini A, Cristino S, Grassi F, Cavallo C, Cattini L, Tonnarelli B, Manferdini C, Facchini A (2007) CCL20 chemokine induces both osteoblast proliferation and osteoclast differentiation: Increased levels of CCL20 are expressed in subchondral bone tissue of rheumatoid arthritis patients. J Cell Physiol 210 (3):798-806. doi:10.1002/jcp.20905

5. McKenzie JA, Bixby EC, Silva MJ (2011) Differential gene expression from microarray analysis distinguishes woven and lamellar bone formation in the rat ulna following mechanical loading. PLoS One 6 (12):e29328. doi:10.1371/journal.pone.0029328

6. Zannettino AC, Farrugia AN, Kortesidis A, Manavis J, To LB, Martin SK, Diamond P, Tamamura H, Lapidot T, Fujii N, Gronthos S (2005) Elevated serum levels of stromal-derived factor-1alpha are associated with increased osteoclast activity and osteolytic bone disease in multiple myeloma patients. Cancer Res 65 (5):1700-1709. doi:10.1158/0008-5472.CAN-04-1687 
7. Choi SJ, Cruz JC, Craig F, Chung H, Devlin RD, Roodman GD, Alsina M (2000) Macrophage inflammatory protein 1-alpha is a potential osteoclast stimulatory factor in multiple myeloma. Blood 96 (2):671-675

8. Han JH, Choi SJ, Kurihara N, Koide M, Oba Y, Roodman GD (2001) Macrophage inflammatory protein-1alpha is an osteoclastogenic factor in myeloma that is independent of receptor activator of nuclear factor kappaB ligand. Blood 97 (11):3349-3353

9. Fuller K, Owens JM, Chambers TJ (1995) Macrophage inflammatory protein-1 alpha and IL-8 stimulate the motility but suppress the resorption of isolated rat osteoclasts. J Immunol 154 (11):6065-6072

10. Yano S, Mentaverri R, Kanuparthi D, Bandyopadhyay S, Rivera A, Brown EM, Chattopadhyay N (2005) Functional expression of beta-chemokine receptors in osteoblasts: role of regulated upon activation, normal T cell expressed and secreted (RANTES) in osteoblasts and regulation of its secretion by osteoblasts and osteoclasts. Endocrinology 146 (5):2324-2335. doi:10.1210/en.20050065

11. Moreaux J, Hose D, Kassambara A, Reme T, Moine P, Requirand G, Goldschmidt H, Klein B (2011) Osteoclast-gene expression profiling reveals osteoclast-derived CCR2 chemokines promoting myeloma cell migration. Blood 117 (4):1280-1290. doi:10.1182/blood-2010-04-279760 12. Palmqvist P, Persson E, Conaway HH, Lerner UH (2002) IL-6, leukemia inhibitory factor, and oncostatin M stimulate bone resorption and regulate the expression of receptor activator of NFkappa B ligand, osteoprotegerin, and receptor activator of NF-kappa B in mouse calvariae. J Immunol 169 (6):3353-3362

13. Tangirala RK, Murao K, Quehenberger O (1997) Regulation of expression of the human monocyte chemotactic protein-1 receptor (hCCR2) by cytokines. J Biol Chem 272 (12):8050-8056 14. Wise GE, Frazier-Bowers S, D'Souza RN (2002) Cellular, molecular, and genetic determinants of tooth eruption. Crit Rev Oral Biol Med 13 (4):323-334 
15. Kim MS, Day CJ, Morrison NA (2005) MCP-1 is induced by receptor activator of nuclear factor-\{kappa $\}$ B ligand, promotes human osteoclast fusion, and rescues granulocyte macrophage colony-stimulating factor suppression of osteoclast formation. J Biol Chem 280 (16):16163-16169. doi:10.1074/jbc.M412713200

16. Li X, Liu H, Qin L, Tamasi J, Bergenstock M, Shapses S, Feyen JH, Notterman DA, Partridge NC (2007) Determination of dual effects of parathyroid hormone on skeletal gene expression in vivo by microarray and network analysis. J Biol Chem 282 (45):33086-33097. doi:10.1074/jbc.M705194200

17. Richards CD, Langdon C, Deschamps P, Pennica D, Shaughnessy SG (2000) Stimulation of osteoclast differentiation in vitro by mouse oncostatin $\mathrm{M}$, leukaemia inhibitory factor, cardiotrophin-1 and interleukin 6: synergy with dexamethasone. Cytokine 12 (6):613-621. doi:10.1006/cyto.1999.0635

18. Walker EC, McGregor NE, Poulton IJ, Solano M, Pompolo S, Fernandes TJ, Constable MJ, Nicholson GC, Zhang JG, Nicola NA, Gillespie MT, Martin TJ, Sims NA (2010) Oncostatin M promotes bone formation independently of resorption when signaling through leukemia inhibitory factor receptor in mice. J Clin Invest 120 (2):582-592. doi:10.1172/JCI40568

19. Kidd LJ, Cowling NR, Wu AC, Kelly WL, Forwood MR (2011) Bisphosphonate treatment delays stress fracture remodeling in the rat ulna. J Orthop Res 29 (12):1827-1833. doi:10.1002/jor.21464

20. Lisignoli G, Toneguzzi S, Grassi F, Piacentini A, Tschon M, Cristino S, Gualtieri G, Facchini A (2002) Different chemokines are expressed in human arthritic bone biopsies: IFN-gamma and IL-6 differently modulate IL-8, MCP-1 and rantes production by arthritic osteoblasts. Cytokine 20 (5):231-238

21. Lisignoli G, Toneguzzi S, Pozzi C, Piacentini A, Grassi F, Ferruzzi A, Gualtieri G, Facchini A (1999) Chemokine expression by subchondral bone marrow stromal cells isolated from osteoarthritis (OA) and rheumatoid arthritis (RA) patients. Clin Exp Immunol 116 (2):371-378 
22. Sims NA, Walsh NC (2010) GP130 cytokines and bone remodelling in health and disease. BMB Rep 43 (8):513-523

23. Somjen D, Binderman I, Berger E, Harell A (1980) Bone remodelling induced by physical stress is prostaglandin E2 mediated. Biochim Biophys Acta 627 (1):91-100

24. Partridge NC, Kemp BE, Veroni MC, Martin TJ (1981) Activation of adenosine 3',5'monophosphate-dependent protein kinase in normal and malignant bone cells by parathyroid hormone, prostaglandin E2, and prostacyclin. Endocrinology 108 (1):220-225

25. Okamatsu Y, Kim D, Battaglino R, Sasaki H, Spate U, Stashenko P (2004) MIP-1 gamma promotes receptor-activator-of-NF-kappa-B-ligand-induced osteoclast formation and survival. J Immunol 173 (3):2084-2090

26. Onan D, Allan EH, Quinn JM, Gooi JH, Pompolo S, Sims NA, Gillespie MT, Martin TJ (2009) The chemokine Cxcl1 is a novel target gene of parathyroid hormone (PTH)/PTH-related protein in committed osteoblasts. Endocrinology 150 (5):2244-2253. doi:10.1210/en.2008-1597

27. Wright LM, Maloney W, Yu X, Kindle L, Collin-Osdoby P, Osdoby P (2005) Stromal cellderived factor-1 binding to its chemokine receptor CXCR4 on precursor cells promotes the chemotactic recruitment, development and survival of human osteoclasts. Bone 36 (5):840-853. doi:10.1016/j.bone.2005.01.021

28. Kim MS, Magno CL, Day CJ, Morrison NA (2006) Induction of chemokines and chemokine receptors CCR2b and CCR4 in authentic human osteoclasts differentiated with RANKL and osteoclast like cells differentiated by MCP-1 and RANTES. J Cell Biochem 97 (3):512-518. doi:10.1002/jcb.20649

29. Mantila Roosa SM, Liu Y, Turner CH (2011) Gene expression patterns in bone following mechanical loading. J Bone Miner Res 26 (1):100-112. doi:10.1002/jbmr.193

30. Sample SJ, Collins RJ, Wilson AP, Racette MA, Behan M, Markel MD, Kalscheur VL, Hao Z, Muir P (2010) Systemic effects of ulna loading in male rats during functional adaptation. J Bone Miner Res 25 (9):2016-2028. doi:10.1002/jbmr.101 
31. Jay PR, Centrella M, Lorenzo J, Bruce AG, Horowitz MC (1996) Oncostatin-M: a new bone active cytokine that activates osteoblasts and inhibits bone resorption. Endocrinology 137 (4):11511158

8

10

11

12

13

14

15

16

17

18

19

20

21

22

23

24

25

26

27

28

29

30

31

32

33

34

35

36

37

38

39

40

41

42

43

44

45

46

47

48

49

50

51

52

53

54

55

56

57

58

59

60 


\section{FIGURE LEGENDS}

Figure 1. Relative mRNA expression of each target gene in unloaded rat ulnae at baseline. The fold difference of MCP-1, relative to RANTES (0.49), CCR1 (0.95) and CCR2 (1.16) were not significant; but MCP-1 was expressed at significantly higher fold levels than MIP1 $\alpha$ (164.2; P < 0.001), $\operatorname{OSM}(34.5 ; \mathrm{P}<0.001)$ and $\operatorname{OSMr}(8.8, \mathrm{P}<0.01)$. Transcript level is relative to housekeeping genes HPRT and GAPDH.

Figure 2. Gene expression of chemokine MCP-1, and the receptors CCR1, CCR2; and serum protein level of MCP-1 after initiation of SFx. (A) Relative to the ULC, an early increase in MCP-1 gene expression occurred $4 \mathrm{~h}$ post loading, and declined markedly by day 4; but remained significantly greater than the contralateral ulna to D14. Both CCR1 (B) and CCR2 (C) gene expression marginally increased over the time course compared to the ULC. CCR1 was significantly greater than ULC at Day 7, and increased to day 14. Relative to ULC, CCR2 peaked at D14 after loading (C), but was significantly greater in loaded ulnae relative to the contralateral side from $4 \mathrm{~h}$. Serum protein levels of MCP-1 followed a similar trend for its gene expression, peaking by Day 1 and decreased to basal levels by D4 (D) after SFx initiation. Transcript level is relative to housekeeping genes HPRT and GAPDH. Left ulnae were used as contralateral controls. ULC = unloaded control. $* * *=\mathrm{P}<0.001, * *=\mathrm{P}<0.01, *=\mathrm{P}<0.05$ compared to ULC; $\{$ show pairwise differences between left and right ulnae, $\mathrm{P}<0.05$.

Figure 3. Localization of MCP-1 mRNA by ISH in bone tissue adjacent to the SFx exit point 7 days after mechanical loading. MCP-1 mRNA can be localized in osteoblastic cells in woven bone at the fracture exit point (A, small arrows), and bone marrow cells (D), but was not localized in osteocytes at any time point (C). Sense probe is negative for non-specific staining (B). Scale bar = $50 \mu \mathrm{M} . \mathrm{WoB}=$ woven bone, Thick arrow $=$ original periosteal margin. $\mathrm{Ot}=$ osteocytes 
Figure 4. Localization of MCP-1 protein by IHC in bone tissue adjacent to the SFx exit point 1, 4 and 7 days after mechanical loading. MCP-1 protein is localized in osteoblastic cells in the periosteum (Ps) 1 day following loading (A, small arrow); and in the woven bone at the fracture exit point at 4 (B) and 7 days after loading (C). Osteocytes adjacent to, and distant from, the SFx were negative for MCP1 staining (E); but bone marrow cells were positive (F). Isotype controls (D) were negative for non-specific staining. The images counterstained with hematoxylin. Scale bar $=$ $50 \mu \mathrm{M} . \mathrm{WoB}=$ woven bone, Thick arrow $=$ original periosteal margin. $\mathrm{Ot}=$ osteocytes 
Table 1: Taqman primers used for the detection of target genes in the experiment

\begin{tabular}{ccc}
\hline Gene & Applied Biosystems Assay ID & Amplicon size (bp) \\
\hline HPRT & Rn01527840_m1 & 64 \\
GAPDH & Rn01775763_g1 & 174 \\
MCP-1 & Rn00580555_m1 & 95 \\
MIP1a & Rn00564660_m1 & 76 \\
RANTES & Rn00579590_m1 & 80 \\
CCR1 & Rn00571950_s1 & 96 \\
CCR2 & Rn01637698_s1 & 103 \\
OSM & Rn01752533_g1 & 81 \\
OSMr & Rn01402599_m1 & 85 \\
\hline
\end{tabular}


Table 2: Summary of fold changes in gene expression of target genes between loaded limbs and unloaded control (ULC) limbs, and loaded limbs and their contralateral control limb. NS = non significant

\begin{tabular}{|c|c|c|c|c|c|}
\hline Time & Gene & Fold differences to ULC & P-value & $\begin{array}{l}\text { Fold differences to } \\
\text { contralateral limb }\end{array}$ & P-value \\
\hline \multirow[t]{7}{*}{$4 \mathrm{~h}$} & MCP1 & 30.4 & $\mathrm{P}<0.0001$ & 33.4 & $\mathrm{P}<0.03$ \\
\hline & MIP1a & 1.3 & NS & 0.8 & NS \\
\hline & RANTES & 1.6 & NS & 0.7 & NS \\
\hline & CCR1 & 1.3 & NS & 1.5 & NS \\
\hline & CCR2 & 2.7 & NS & 2.6 & $\mathrm{P}<0.02$ \\
\hline & OSM & 0.5 & NS & 0.7 & NS \\
\hline & OSMr & 2.6 & $\mathrm{P}<0.05$ & 2.3 & $\mathrm{P}<0.01$ \\
\hline \multirow[t]{7}{*}{ D1 } & MCP1 & 11.8 & $\mathrm{P}<0.0001$ & 13.2 & $\mathrm{P}<0.0001$ \\
\hline & MIP1a & 1.3 & NS & 1.2 & NS \\
\hline & RANTES & 0.9 & NS & 1.1 & NS \\
\hline & CCR1 & 2.1 & NS & 1.5 & NS \\
\hline & CCR2 & 2.6 & NS & 2.6 & $\mathrm{P}<0.04$ \\
\hline & OSM & 1.0 & NS & 1.3 & NS \\
\hline & OSMr & 2.2 & NS & 1.2 & NS \\
\hline \multirow[t]{2}{*}{ D4 } & MCP1 & 2.8 & NS & 2.0 & $\mathrm{P}<0.02$ \\
\hline & MIP1a & 1.5 & NS & 2.0 & NS \\
\hline
\end{tabular}




$\begin{array}{ccccc}\text { RANTES } & 0.8 & \text { NS } & 1.7 & \text { NS } \\ \text { CCR1 } & 2.4 & \text { NS } & 1.7 & \mathrm{P}<0.03 \\ \text { CCR2 } & 2.2 & \text { NS } & 3.3 & \mathrm{P}<0.02 \\ \text { OSM } & 0.8 & \text { NS } & 0.7 & \text { NS } \\ \text { OSMr } & 1.9 & \text { NS } & 0.8 & \text { NS }\end{array}$

\begin{tabular}{|c|c|c|c|c|c|}
\hline \multirow[t]{7}{*}{ D7 } & MCP1 & 2.5 & NS & 2.2 & $\mathrm{P}<0.003$ \\
\hline & MIP1a & 2.2 & NS & 4.2 & $\mathrm{P}<0.01$ \\
\hline & RANTES & 1.1 & NS & 2.5 & $\mathrm{P}<0.03$ \\
\hline & CCR1 & 2.7 & $\mathrm{P}<0.05$ & 2.2 & $\mathrm{P}<0.005$ \\
\hline & CCR2 & 3.2 & NS & 7.2 & $\mathrm{P}<0.004$ \\
\hline & OSM & 1.5 & NS & 1.3 & NS \\
\hline & OSMr & 2.3 & NS & 0.7 & NS \\
\hline \multirow[t]{7}{*}{ D14 } & MCP1 & 2.1 & NS & 2.1 & $\mathrm{P}<0.03$ \\
\hline & MIP1a & 1.3 & NS & 1.1 & NS \\
\hline & RANTES & 2.2 & NS & 2.0 & NS \\
\hline & CCR1 & 3.0 & $\mathrm{P}<0.001$ & 2.2 & NS \\
\hline & CCR2 & 4.2 & $\mathrm{P}<0.05$ & 2.5 & NS \\
\hline & OSM & 1.6 & NS & 1.6 & NS \\
\hline & OSMr & 1.8 & NS & 0.7 & NS \\
\hline
\end{tabular}




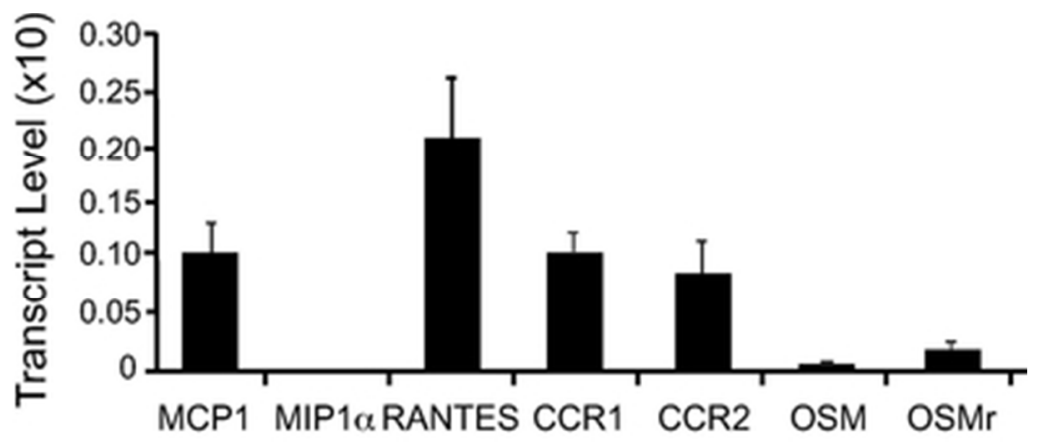

Relative mRNA expression of each target gene in unloaded rat ulnae at baseline. The fold difference of MCP1 , relative to RANTES (0.49), CCR1 (0.95) and CCR2 (1.16) were not significant; but MCP-1 was expressed at significantly higher fold levels than MIP1a (164.2; $\mathrm{P}<0.001)$, OSM (34.5; $\mathrm{P}<0.001)$ and OSMr (8.8, $\mathrm{P}<$ $0.01)$. Transcript level is relative to housekeeping genes HPRT and GAPDH $33 \times 13 \mathrm{~mm}(300 \times 300 \mathrm{DPI})$ 

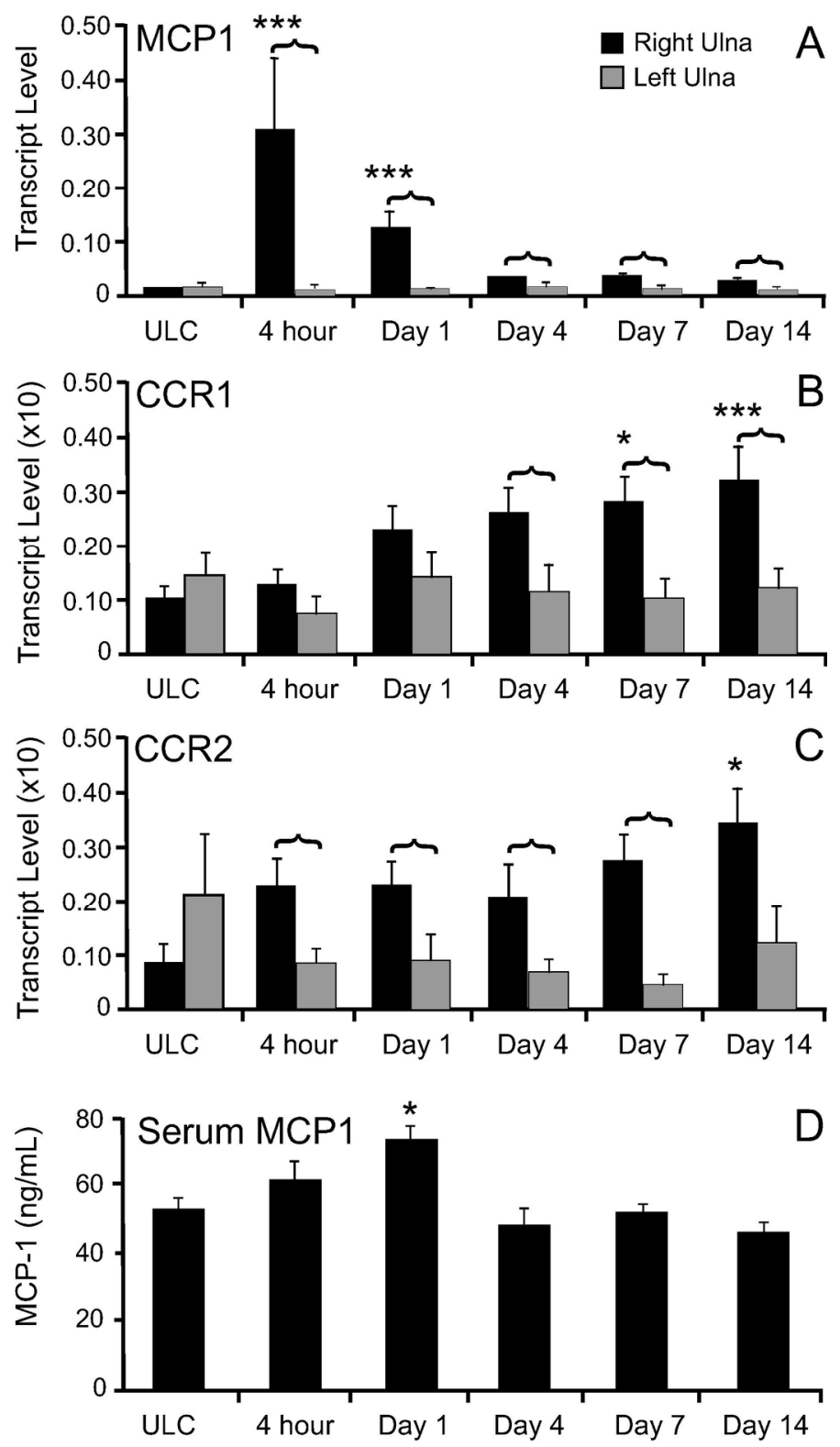

Gene expression of chemokine MCP-1, and the receptors CCR1, CCR2; and serum protein level of MCP-1 after initiation of SFX. (A) Relative to the ULC, an early increase in MCP-1 gene expression occurred $4 \mathrm{~h}$ post loading, and declined markedly by day 4; but remained significantly greater than the contralateral ulna to D14. Both CCR1 (B) and CCR2 (C) gene expression marginally increased over the time course compared to the ULC. CCR1 was significantly greater than ULC at Day 7, and increased to day 14. Relative to ULC, CCR2 peaked at D14 after loading (C), but was significantly greater in loaded ulnae relative to the contralateral side from $4 \mathrm{~h}$. Serum protein levels of MCP-1 followed a similar trend for its gene expression, peaking by

Day 1 and decreased to basal levels by D4 (D) after SFx initiation. Transcript level is relative to housekeeping genes HPRT and GAPDH. Left ulnae were used as contralateral controls. ULC $=$ unloaded control. $* * *=\mathrm{P}<0.001, * *=\mathrm{P}<0.01, *=\mathrm{P}<0.05$ compared to ULC; $\{$ show pairwise differences between left and right ulnae, $\mathrm{P}<0.05$. $138 \times 242 \mathrm{~mm}(300 \times 300$ DPI $)$ 
1

2

3

4

5

6

7

8

9

10

11

12

13

14

15

16

17

18

19

20

21

22

23

24

25

26

27

28

29

30

31

32

33

34

35

36

37

38

39

40

41

42

43

44

45

46

47

48

49

50

51

52

53

54

55

56

57

58

59

60 
Localization of MCP-1 mRNA by ISH in bone tissue adjacent to the SFx exit point 7 days after mechanical loading. MCP-1 mRNA can be localized in osteoblastic cells in woven bone at the fracture exit point ( $A$, small arrows), and bone marrow cells (D), but was not localized in osteocytes at any time point (C). Sense probe is negative for non-specific staining (B). Scale bar $=50 \mu \mathrm{M}$. WoB $=$ woven bone, Thick arrow $=$ original periosteal margin. Ot=osteocytes $64 \times 49 \mathrm{~mm}(600 \times 600 \mathrm{DPI})$ 

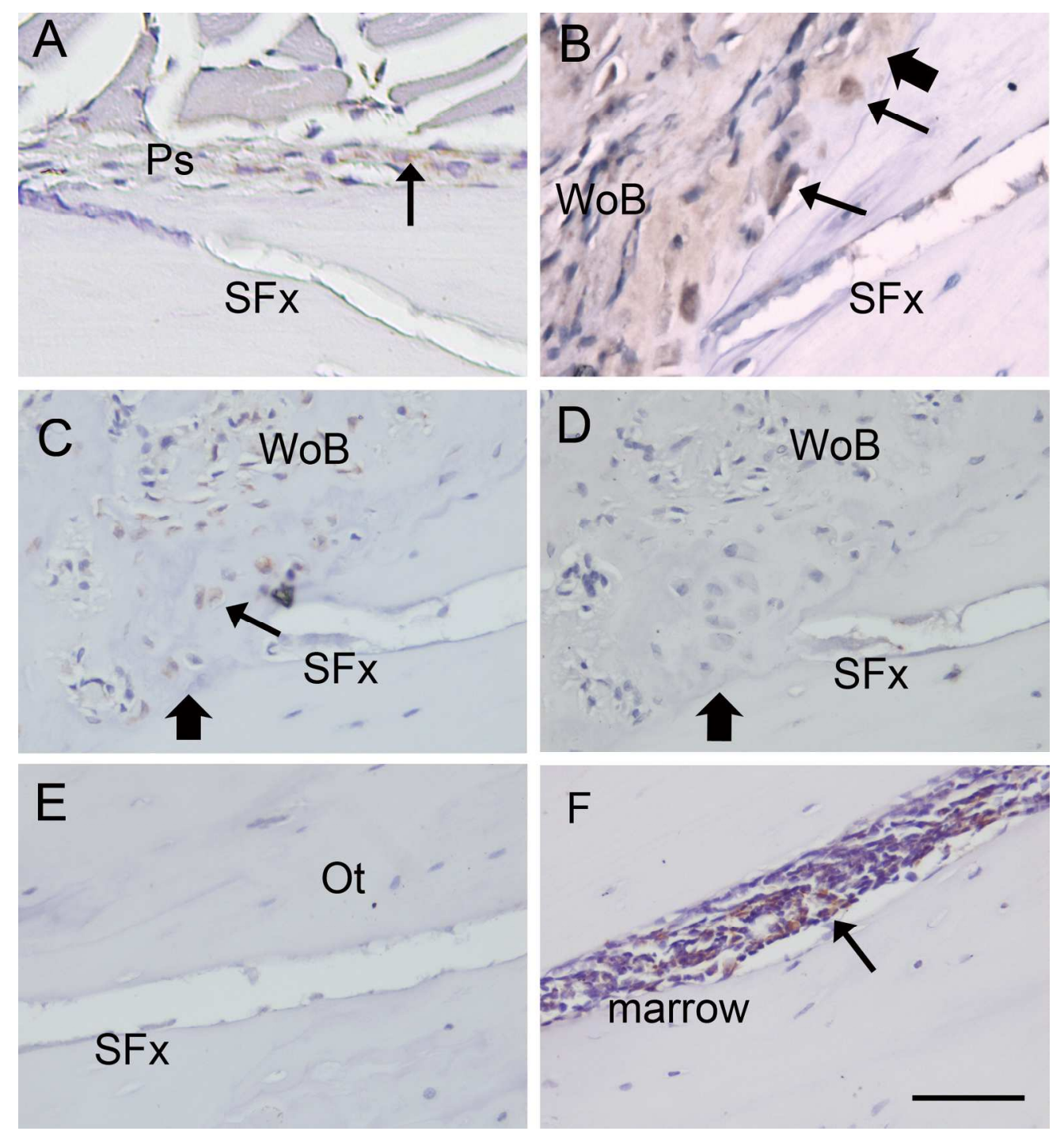

Localization of MCP-1 protein by IHC in bone tissue adjacent to the SFx exit point 1,4 and 7 days after mechanical loading. MCP-1 protein is localized in osteoblastic cells in the periosteum (Ps) 1 day following loading (A, small arrow); and in the woven bone at the fracture exit point at 4 (B) and 7 days after loading

(C). Osteocytes adjacent to, and distant from, the SFx were negative for MCP1 staining (E); but bone marrow cells were positive $(F)$. Isotype controls $(D)$ were negative for non-specific staining. The images counterstained with hematoxylin. Scale bar $=50 \mu \mathrm{M}$. WoB $=$ woven bone, Thick arrow $=$ original periosteal margin. Ot $=$ osteocytes $91 \times 99 \mathrm{~mm}(600 \times 600 \mathrm{DPI})$ 